\title{
High-Speed Data Transmission over Flexible Multimode Polymer Waveguides Under Flexure
}

\author{
Nikolaos Bamiedakis, Fengyuan Shi, Daping Chu, Senior Member, IEEE, \\ Richard V. Penty, Senior Member, IEEE and Ian H. White, Fellow, IEEE
}

\begin{abstract}
Polymer multimode waveguides on flexible substrates enable the formation of bendable low-cost optical interconnects that can be deployed in a wide range of applications. However, the highly-multimoded nature of such guides in combination with the stress and mode mixing induced due to sample bending raise important concerns about the effect that sample flexure has on their bandwidth performance and potential to support high-speed data transmission. In this work therefore, we present data transmission studies on a $1 \mathrm{~m}$ long flexible spiral waveguide when flexure is applied. The flexible polymer sample is bent $180^{\circ}$ around a cylindrical mandrel and the loss and frequency response of the waveguide are obtained for radii of curvature down to $4 \mathrm{~mm}$ and are compared with the performance obtained when no flexure is applied. The BER performance of the respective optical link is also recorded at data rates up to $40 \mathrm{~Gb} / \mathrm{s}$. A flat frequency response up to at least $30 \mathrm{GHz}$ is demonstrated for all bending radii applied and error-free $\left(B E R<10^{-12}\right)$ data transmission is achieved for all data rates studied up to $40 \mathrm{~Gb} / \mathrm{s}$. The results clearly demonstrate that sample flexing does not result in any significant transmission impairments in such links and highlight the strong potential of this technology for use in high-speed board-level interconnections.
\end{abstract}

Index Terms - optical interconnects, polymer waveguides, multimode waveguides, flexible substrates, optical communications, board-level communications

\section{INTRODUCTION}

Optical interconnects have attracted great interest in recent years for use in short-reach communication links in high-performance electronic systems such as data centers, data storage systems and supercomputers. Optical links provide significant performance advantages over conventional electrical interconnects, namely higher bandwidth, lower power consumption at high data rates $(>10 \mathrm{~Gb} / \mathrm{s})$, increased density and relaxed thermal management requirements [1]. Multimode polymer waveguides in particular, are an attractive technology

Manuscript received April xx, 2018; revised May xx, 2018; accepted May xx, 2018. Date of publication June xx, 2018; date of current version August xx, 2018.

The authors would like to acknowledge Dow Corning for the provision of the polymer samples through the CAPE OIC Future project, Chalmers University for the provision of the high-speed VCSELs and Jaguar Land Rover for the financial support through the CAPE LEASA Project. Additional data related to this publication is available at the data repository https://www.repository.cam.ac.uk/handle/xxxxxx.

N. Bamiedakis, F. Shi, D. Chu, R. V. Penty and I. H. White, are with the Electrical Engineering Division, Engineering Department, University of Cambridge, CB3 0FA Cambridge, UK (e-mail: nb301@ cam.ac.uk).

Color versions of one or more of the figures in this paper are available online at http://ieeexplore.ieee.org.

Digital Object Identifier 10.1109/xxxx for use in board-level interconnects as they can enable the cost-effective formation of optical backplanes and high-speed chip-to-chip optical links directly integrated onto conventional printed circuit boards (PCBs) [2,3]. A leading class of such polymeric optical interconnects comprise siloxane-based waveguides. Siloxane materials have been shown to possess the necessary mechanical and thermal properties to withstand the manufacturing processes of standard PCBs, and exhibit good environmental stability, long lifetimes and low absorption (< $0.04 \mathrm{~dB} / \mathrm{cm}$ ) at the datacommunication wavelength of $850 \mathrm{~nm}$ $[4,5]$. Large-size waveguides, with dimensions typically in the range 30 to $70 \mu \mathrm{m}$, are employed for the formation of on-board optical interconnects, as these offer relaxed alignment tolerances and therefore enable cost-effective board assembly using standard tools of the electronics industry. For example, $50-\mu \mathrm{m}$ wide waveguides offer $1 \mathrm{~dB}$ alignment tolerances of \pm 10 $\mu \mathrm{m}$, enabling thereby system assembly with standard pick-and-place tools [2]. In recent years, numerous studies on multimode waveguides and waveguide components have been carried out and various system demonstrators have been produced. Record non-return-to-zero (NRZ) $40 \mathrm{~Gb} / \mathrm{s}$ and 4-level pulse-amplitude modulation (PAM-4) $56 \mathrm{~Gb} / \mathrm{s}$ data transmission have been achieved over a $1 \mathrm{~m}$ long polymer multimode waveguide on a rigid substrate [6,7]. Additionally, experimental and theoretical bandwidth studies on such waveguides have demonstrated that bandwidth-length products larger than $60 \mathrm{GHz} \times \mathrm{m}$ can be achieved from such waveguide technology applying refractive index engineering and launch conditioning schemes [8].

The further formation of such polymer waveguides on flexible substrates can provide significant additional benefits and result in thin, lightweight and bendable short-reach optical interconnects that can be used over a wider application range. Flexible polymer waveguide ribbons can be deployed as detachable and reconfigurable board-to-board or chip-to-chip optical links and can enable high-speed optical interconnection in environments where shape and weight conformity are important, such as in automotive and aircraft applications, and in electronic systems that have movable parts or that are susceptible to mechanical vibrations. Various flexible polymer waveguide technologies have been developed in recent years and related opto-electronic subassemblies have been reported [9-12]. Flexible siloxane-based waveguides have been fabricated with good performance [12], while we have recently reported detailed studies on the loss and bandwidth performance of such flexible waveguide ribbons when bending or twisting is applied $[13,14]$. Although data transmission at rates up to $25 \mathrm{~Gb} / \mathrm{s}$ has been reported over flexible polymer multimode waveguides $[9,15,16]$, these demonstrations only 
involved straight waveguides with short lengths of $\leq 20 \mathrm{~cm}$, whilst no particular studies have been carried out on their performance under flexure. Additionally, bandwidth studies on $90^{\circ}$ waveguide bends of fixed radius fabricated on rigid substrates have been reported in [17] with good bandwidth performance demonstrated. However, in such rigid waveguide bends with fixed curvature, no stress is induced due to the bending while the length of the bend sections is also very short $(\sim 3 \mathrm{~cm})$. The flexure of flexible samples can affect mode mixing in the waveguides and introduce selective additional mode loss due to the induced stress and can therefore have a significant impact on their bandwidth performance. Any such effects become more significant the higher the data rate, the longer the waveguides employed and the stronger the flexure applied. In this work therefore, we present data transmission studies at data rates up to $40 \mathrm{~Gb} / \mathrm{s}$ on a relatively-long flexible polymer waveguide under flexure. Loss, $S_{21}$ and bit-error-rate (BER) measurements are carried out on a flexible $1 \mathrm{~m}$ long spiral waveguide when the sample is bent $180^{\circ}$ with a varying radius of curvature down to $4 \mathrm{~mm}$ and compared to the performance obtained when no flexure is applied. Similar good performance is observed under flexure, with error-free (BER < $10^{-12}$ ) $40 \mathrm{~Gb} / \mathrm{s}$ data transmission achieved for even the smaller radius of $4 \mathrm{~mm}$. The results demonstrate that no significant transmission impairments are induced due to the sample bending and indicate that no detrimental mode mixing takes place along the waveguide bends. The results demonstrate the excellent optical and mechanical properties of this technology and highlight its potential for use in real-world systems.

The remainder of this paper is structured as follows. Section II presents the flexible waveguide sample used in this work and the employed experimental setup. Section III reports on the data transmission studies and Section IV concludes the paper.

\section{WAVEGUIDE SAMPLE AND EXPERIMENTAL SETUP}

The $1 \mathrm{~m}$ long polymer spiral waveguide used in this work is fabricated from siloxane materials (Dow Corning ${ }^{\circledR}$ WG-1020 core and XX-1023 cladding) on 6-inch $125 \mu \mathrm{m}$-thick polyimide substrate using conventional photolithography. The refractive index difference between the core and cladding materials $\Delta \mathrm{n}$ is $\sim 0.02$ at $850 \mathrm{~nm}$, while the waveguide cross section is $\sim 55 \times 58$ $\mu \mathrm{m}^{2}$. The bottom and top cladding thickness are $\sim 40 \mu \mathrm{m}$ and 20 $\mu \mathrm{m}$ respectively while the minimum radius of the spiral waveguide is $\sim 40 \mathrm{~mm}$ for the circular part and $\sim 20 \mathrm{~mm}$ for the inflection bends in the middle section. Fig. 1 shows images of the flexible polymer sample and spiral waveguide when no flexure is applied as well as the waveguide cross section. The input and output waveguide facets are exposed using a dicing saw, while no polishing steps are undertaken to improve the facet quality.

The light transmission performance of the sample is measured when no flexure (flat sample, $\mathrm{R}=\infty$ ) is applied and when the sample is bent $180^{\circ}$ around cylindrical mandrels of different radii of curvature $(\mathrm{R}=12,8$ and $4 \mathrm{~mm})$. The smaller radius tested $(4 \mathrm{~mm})$ introduces sufficiently low excess loss which allows adequate optical power at the receiver $(\mathrm{Rx})$ for error-free $\left(\mathrm{BER}<10^{-12}\right) 40 \mathrm{~Gb} / \mathrm{s}$ data transmission over the $1 \mathrm{~m}$ long waveguide. Fig. 2 depicts the experimental setup used in the measurements while Fig. 3 shows images of the flexible sample with flexure applied. The two sample ends are mounted onto translation stages and appropriately positioned to ensure tight sample wrapping around the mandrel for each measurement. All measurements are carried out at $850 \mathrm{~nm}$ using a vertical-cavity surface-emitting laser (VCSEL) with a bandwidth of $25 \mathrm{GHz}$ and a $30 \mathrm{GHz}$ fibre-coupled (VIS $\mathrm{D} 30-850 \mathrm{M}$ ) photodetector (PD). A pair of $\times 16$ (numerical aperture of 0.32) microscope objectives is employed at each waveguide end to couple the light in and out of the spiral waveguide. The use of the lenses is preferred over multimode fibre patchcords as it minimises coupling losses and ensures adequate optical power at the receiver to achieve $40 \mathrm{~Gb} / \mathrm{s}$ transmission even for the smaller $4 \mathrm{~mm}$ radius. A free-space variable optical attenuator (VOA) is employed in the link to control the received optical power and enable BER measurements. The VCSEL is directly modulated by a $2^{7}-1$ pseudo-random binary sequence via a high-bandwidth bias tee, while at the receiver end a $38 \mathrm{GHz} \mathrm{RF}$ amplifier (SHF 810) is used to amplify the received signal to suitable amplitudes for BER measurements. A vector network analyzer (VNA, Agilent $8722 \mathrm{ET}$ ) is used to obtain the small signal frequency response of the optical link for each applied radius of curvature, while a BER test set (Anritsu MP1800A) and a wide-bandwidth digital sampling oscilloscope (Agilent 86100A) are employed to record the eye diagrams of the received signal and respective BER performance for each link. The back-to-back (b2b) optical link without the flexible waveguide [Fig. 2(b)] is also tested as it provides a reference for the link performance and enables the extraction of the waveguide frequency response from the measured total link response.
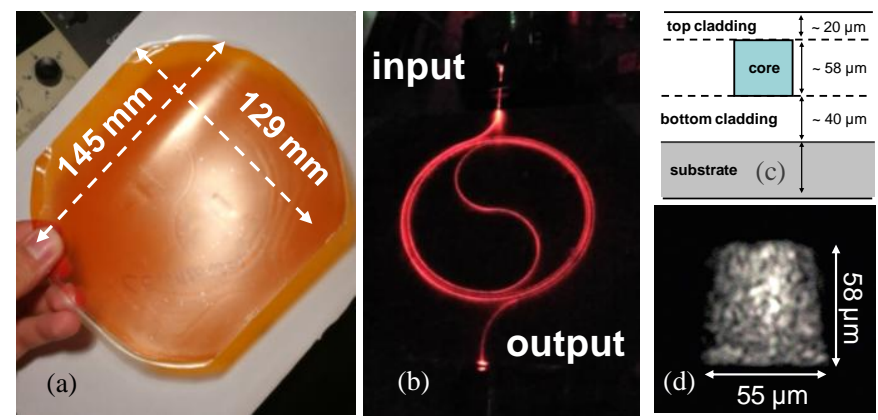

Fig. 1. Image of (a) the flexible waveguide sample with dimensions noted, (b) the spiral waveguide illuminated with red light, (c) schematic of the sample cross section and (d) near-field image of the waveguide output at $850 \mathrm{~nm}$.

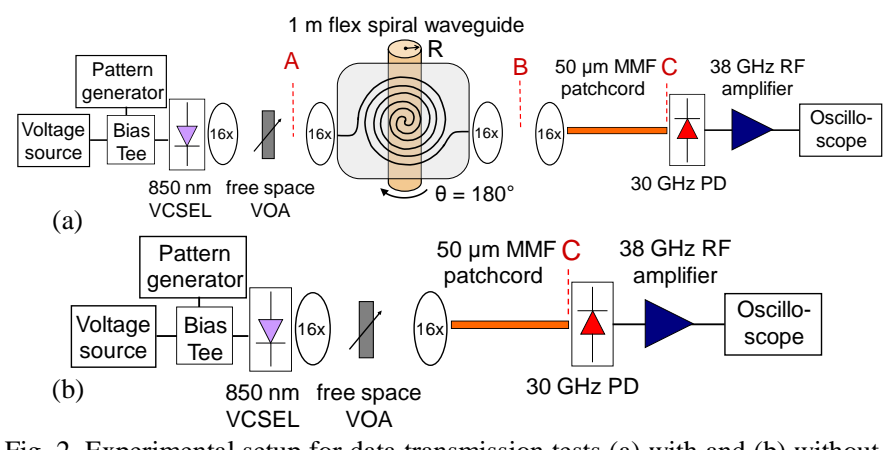

Fig. 2. Experimental setup for data transmission tests (a) with and (b) without (b2b) the $1 \mathrm{~m}$ long spiral waveguide. 

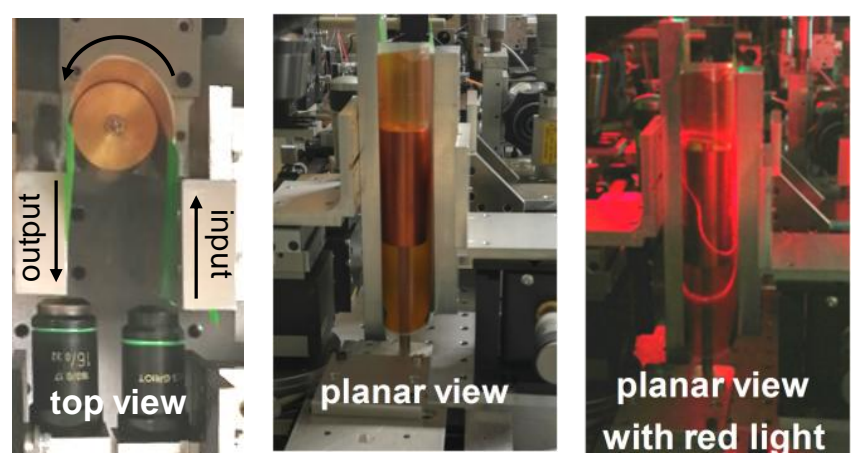

Fig. 3. Images of the sample wrapped around the mandrel of $12 \mathrm{~mm}$ radius and illuminated with red light.

\section{EXPERIMENTAL RESULTS}

The insertion loss of the flexible waveguide [difference in optical power between points $\mathrm{A}$ and $\mathrm{B}$ in Fig. 2(a)] is found to be $6.9,7.0,7.6$ and $8.7 \mathrm{~dB}$ for $\mathrm{R}=\infty$ (flat sample), 12, 8 and 4 $\mathrm{mm}$ respectively. Table I shows the excess loss due to the sample bending and the respective near-field images of the waveguide output for the different radii of curvature. The near-field images show some suppression of the higher-order modes for decreasing bend radius, with reduced light intensity observed towards the waveguide edges.

TABLE I

EXCESS LOSS AND NEAR-FIELD IMAGES

\begin{tabular}{|c|c|c|c|c|}
\hline $\begin{array}{l}\text { Radius } \\
(\mathrm{mm})\end{array}$ & $\infty$ & 12 & 8 & 4 \\
\hline $\begin{array}{l}\text { Excess } \\
\text { bending } \\
\text { loss (dB) }\end{array}$ & 0 & 0.1 & 0.7 & 1.8 \\
\hline $\begin{array}{l}\text { Near - } \\
\text { field } \\
\text { images }\end{array}$ & & & 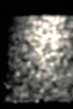 & 6 \\
\hline
\end{tabular}

Fig. 4 shows the normalized frequency response of the optical links studied with and without the $1 \mathrm{~m}$ long spiral waveguide [Fig. 4(a)] and the extracted frequency for the spiral waveguide for the different applied radii of curvature [Fig. 4(b)]. As it can be noticed in Fig. 4(a), the frequency response of the optical link with the flexible waveguide has the same shape as the response recorded for the b2b link, while Fig. 4(b) demonstrates a flat waveguide frequency response up to at least $30 \mathrm{GHz}$ for all bending radii studied, with no significant changes in the shape of the response when the sample is flexed. The results clearly indicate that the bandwidth of the link is limited by the optoelectronic devices used here rather the long spiral waveguide, and demonstrate that the sample bending does not introduce any significant additional dispersion in the link. The obtained results are in agreement with results obtained from bandwidth studies on multimode waveguide bends on rigid substrates [17].

Table II illustrates the recorded eye diagrams at 25, 36 and $40 \mathrm{~Gb} / \mathrm{s}$ for the b2b and waveguide link for the different applied radii. Open eye diagrams are obtained up to $40 \mathrm{~Gb} / \mathrm{s}$ with minimal additional noise and signal distortion observed in the recorded eyes due to sample bending. Fig. 5 shows the BER curves obtained for each data rate and radius studied as a function of the average received optical power [point $\mathrm{C}$ in Fig. 2(a)]. Error-free $\left(B E R<10^{-12}\right)$ data transmission is achieved for all data rates studied and radii of curvature down to $4 \mathrm{~mm}$. It is noticed that sample bending does not significant impact the BER performance of the link. By comparing the BER performance of the link when no flexure is applied $(\mathrm{R}=\infty)$ and with flexure $(\mathrm{R} \leq 12 \mathrm{~mm})$, the power penalty due to the sample bending can be obtained. A worst-case power penalty of $\sim 0.5$ $\mathrm{dB}$ for a BER of $10^{-12}$ is obtained for the $25 \mathrm{~Gb} / \mathrm{s}$ data rate [Fig. 5(a)]. For $40 \mathrm{~Gb} / \mathrm{s}$ transmission, a slightly improved BER performance with decreasing radius is noted [Fig. 5(c)], which can be attributed to the suppression of the higher order modes along the waveguide bend. Similar bandwidth improvements have been observed in in-plane polymer multimode waveguide bends when the bend radius is reduced [17].

(a)
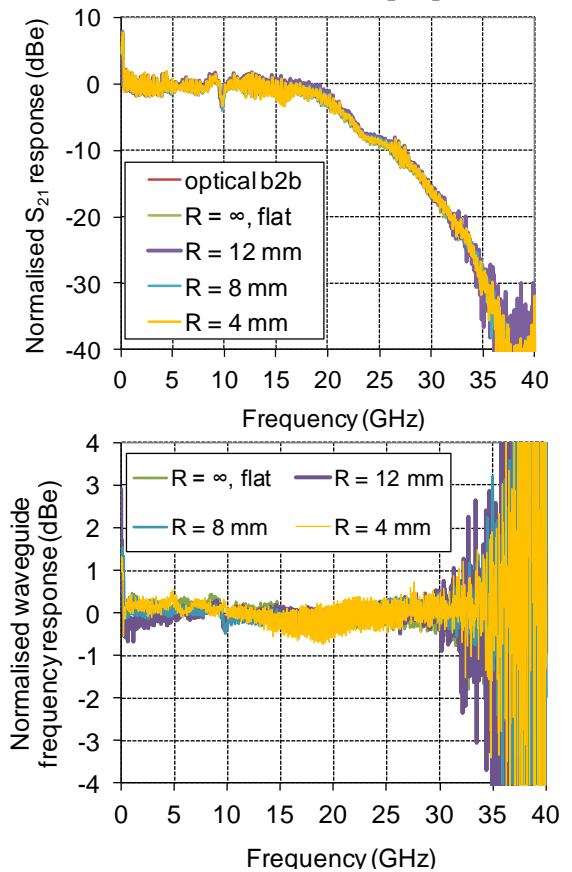

Fig. 4. Normalised frequency response of (a) the optical links studied and (b) the $1 \mathrm{~m}$ long spiral waveguide extracted when the $\mathrm{b} 2 \mathrm{~b}$ response is subtracted.

TABLE II

RECEIVED EYE DIAGRAMS FOR THE B2B AND WAVEGUIDE LINK

\begin{tabular}{|c|c|c|c|}
\hline & $25 \mathrm{~Gb} / \mathrm{s}$ & $36 \mathrm{~Gb} / \mathrm{s}$ & $40 \mathrm{~Gb} / \mathrm{s}$ \\
\hline $\mathrm{b} 2 \mathrm{~b}$ & & & \\
\hline
\end{tabular}


(a)

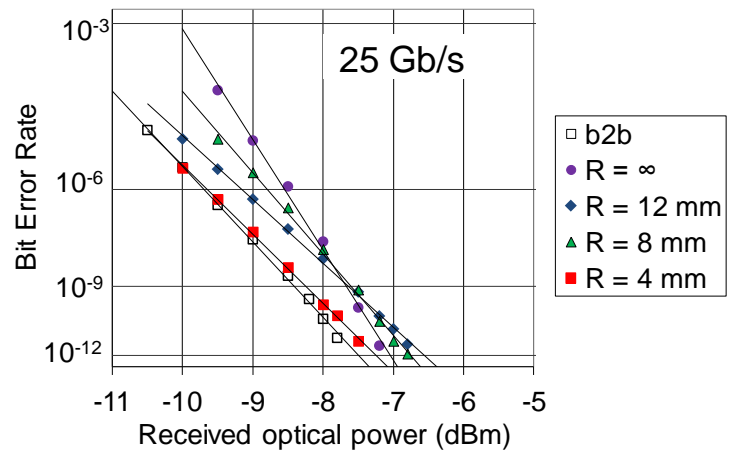

(b)

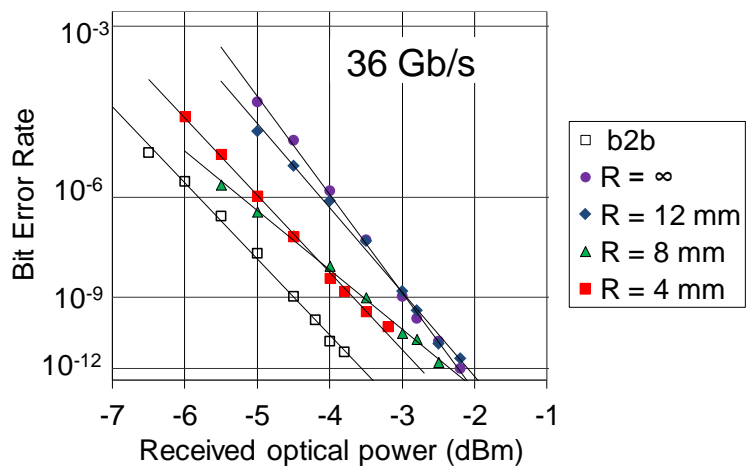

(c)

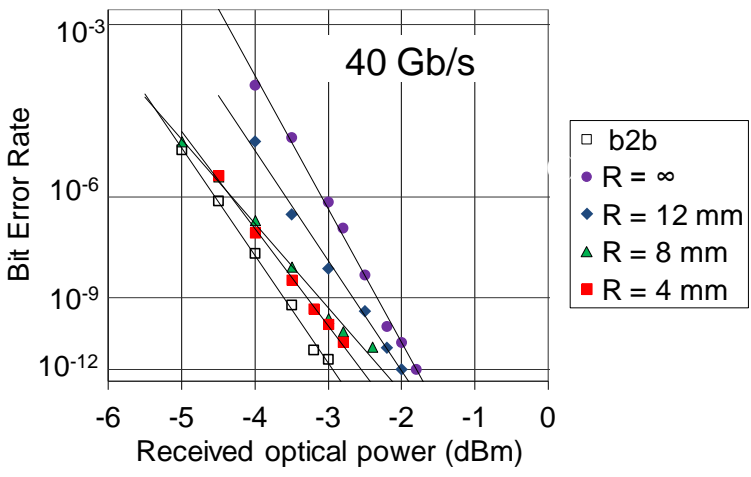

Fig. 5. BER plots at (a) $25 \mathrm{~Gb} / \mathrm{s}$, (b) $36 \mathrm{~Gb} / \mathrm{s}$ and (c) $40 \mathrm{~Gb} / \mathrm{s}$ for the b2b and waveguide link for the different radii applied on the waveguide sample.

The results obtained indicate that for the $1 \mathrm{~m}$ length, radii and data rates studied here (which are relevant to the application), any mode mixing effects in these polymer waveguides due to flexure are weak and don't significantly affect their data transmission capability. However, to better understand the phenomenon in such multimode waveguides and to determine the length and radius beyond which mode mixing becomes important, further studies need to be carried out on waveguides with longer lengths or when micro-bending is applied.

\section{CONCLUSIONS}

Flexible polymer multimode waveguides enable the formation of versatile bendable low-cost optical interconnects. Data transmission studies on such a $1 \mathrm{~m}$ long flexible spiral waveguide demonstrate that sample flexure down to $4 \mathrm{~mm}$ of radius doesn't result in any significant impairment in the high-speed performance of the optical link and indicate that any mode mixing effects due to stress induced from the sample bending are weak. A flat frequency response up to at least 30 $\mathrm{GHz}$ is demonstrated and error-free $\left(\mathrm{BER}<10^{-12}\right) 40 \mathrm{~Gb} / \mathrm{s}$ data transmission is achieved when the sample is bent $180^{\circ}$ with a 4 $\mathrm{mm}$ radius. The results highlight the potential of this optical technology in real-world applications.

\section{REFERENCES}

[1]. M. A. Taubenblatt, "Optical Interconnects for High-Performance Computing," Journal of Lightwave Technology, vol. 30, pp. 448-457, 2012.

[2]. N. Bamiedakis, A. Hashim, J. Beals, R. V. Penty, and I. H. White, "Low-Cost PCB-Integrated 10-Gb/s Optical Transceiver Built With a Novel Integration Method," IEEE Transactions on Components, Packaging and Manufacturing Technology, vol. 3, pp. 592-600, 2013.

[3]. M. Immonen, R. Zhang, M. Press, H. Tang, W. Lei, J. Wu, H. J. Yan, L. X. Zhu, and M. Serbay, "End-to-end Optical 25Gb/s Link Demonstrator with Embedded Waveguides, 90o Out-of-Plane Connector and On-board Optical Transceivers," in $42^{\text {nd }}$ European Conference on Optical Communication (ECOC), pp. 1-3, 2016

[4]. R. S. E. John, C. M. Amb, B. W. Swatowski, W. K. Weidner, M. Halter, T. Lamprecht, and F. Betschon, "Thermally Stable, Low Loss Optical Silicones: A Key Enabler for Electro-Optical Printed Circuit Boards," Journal of Lightwave Technology, vol. 33, pp. 814-819, 2015.

[5]. B. W. Swatowski, C. M. Amb, S. K. Breed, D. J. Deshazer, W. K. Weidner, R. F. Dangel, N. Meier, and B. J. Offrein, "Flexible, stable, and easily processable optical silicones for low loss polymer waveguides," Proc. SPIE 8622, Organic Photonic Materials and Devices XV, pp. 1-11, 2013.

[6]. N. Bamiedakis, C. Jian, P. Westbergh, J. S. Gustavsson, A. Larsson, R. V. Penty, and I. H. White, "40 Gb/s Data Transmission Over a 1-m-Long Multimode Polymer Spiral Waveguide for Board-Level Optical Interconnects," Journal of Lightwave Technology, vol. 33, pp. 882-888, 2015.

[7]. N. Bamiedakis, J. Wei, J. Chen, P. Westbergh, A. Larsson, R. V. Penty, and I. H. White, "56 Gb/s PAM-4 Data Transmission Over a 1 m Long Multimode Polymer Interconnect," in Conference on Lasers and Electro-Optics (CLEO), paper STu4F.5, pp. 1-2, 2015.

[8]. J. Chen, N. Bamiedakis, P. P. Vasilev, T. J. Edwards, C. T. A. Brown, R. V. Penty, and I. H. White, "High-Bandwidth and Large Coupling Tolerance Graded-Index Multimode Polymer Waveguides for On-Board High-Speed Optical Interconnects," Journal of Lightwave Technology, vol. 34, pp. 2934-2940, 2016

[9]. T. Yagisawa, T. Mori, R. Gappa, K. Tanaka, O. Daikuhara, T. Komiyama, and S. Ide, "Structure of 25-Gb/s Optical Engine for QSFP Enabling High-Precision Passive Alignment of Optical Assembly," in $66^{\text {th }}$ Electronic Components and Technology Conference (ECTC), pp. 1099-1104, 2016.

[10]. L. Li, Y. Zou, H. Lin, J. Hu, X. Sun, N.-N. Feng, S. Danto, K. Richardson, T. Gu, and M. Haney, "A Fully-Integrated Flexible Photonic Platform for Chip-to-Chip Optical Interconnects," Journal of Lightwave Technology, vol. 31, pp. 4080-4086, 2013.

[11]. E. Bosman, G. Van Steenberge, B. Van Hoe, J. Missinne, J. Vanfleteren, and P. Van Daele, "Highly Reliable Flexible Active Optical Links," IEEE Photonics Technology Letters, vol. 22, pp. 287-289, 2010.

[12]. R. Dangel, F. Horst, D. Jubin, N. Meier, J. Weiss, B. J. Offrein, B. W. Swatowski, C. M. Amb, D. J. DeShazer, and W. K. Weidner, "Development of Versatile Polymer Waveguide Flex Technology for Use in Optical Interconnects," Journal of Lightwave Technology, vol. 31, pp. 3915-3926, 2013.

[13]. N. Bamiedakis, F. Shi, D. Chu, R. V. Penty, and I. H. White, "Flexible multimode polymer waveguides for versatile high-speed optical interconnects," in International Conference on Transparent Optical Networks (ICTON), paper Tu.D3.2, pp. 1-5, 2017.

[14]. F. Shi, N. Bamiedakis, P. P. Vasil'ev, R. V. Penty, I. H. White, and D. Chu, "Flexible Multimode Polymer Waveguide Arrays for Versatile High-Speed Short-Reach Communication Links," Journal of Lightwave Technology, vol. 36, pp. 2685-2693, 2018.

[15]. T. Shiraishi, T. Yagisawa, T. Ikeuchi, S. Ide, and K. Tanaka, "Cost-effective low-loss flexible optical engine with microlens-imprinted film for high-speed on-board optical interconnection," in $62^{\text {nd }}$ Electronic Components and Technology Conference (ECTC), pp. 1505-1510, 2012.

[16]. F. E. Doany, C. L. Schow, B. G. Lee, R. A. Budd, C. W. Baks, C. K. Tsang, J. U. Knickerbocker, R. Dangel, B. Chan, L. How, C. Carver, H. Jianzhuang, J. Berry, D. Bajkowski, F. Libsch, and J. A. Kash, "Terabit/s-Class Optical PCB Links Incorporating 360-Gb/s Bidirectional $850 \mathrm{~nm}$ Parallel Optical Transceivers," Journal of Lightwave Technology, vol. 30, pp. 560-571, 2012.

[17]. J. Chen, N. Bamiedakis, P. Vasil'ev, R. Penty, and I. H. White, "Bandwidth Enhancement in Multimode Polymer Waveguides Using Waveguide Layout for Optical Printed Circuit Boards," in Optical Fiber Communication Conference (OFC), paper W1E.3, pp. 1-3, 2016. 